\title{
Peak Inspiratory Pressure
}

National Cancer Institute

\section{Source}

National Cancer Institute. Peak Inspiratory Pressure. NCI Thesaurus. Code C120940.

The maximum amount of pressure applied to the lungs during inhalation. 